\title{
RESENHA CRÍTICA DO FILME TITANIC: UMA ANÁLISE HISTÓRICA
}

\section{RESENHA}

OLIVEIRA, Rosane Machado De ${ }^{1}$

OLIVEIRA, Rosane Machado De. Resenha crítica do filme Titanic: Uma análise histórica. Revista Científica Multidisciplinar Núcleo do Conhecimento. Ano 05, Ed. 03, Vol. 05, pp. 54-60. Março de 2020. ISSN: 2448-0959, Link de acesso: https://www.nucleodoconhecimento.com.br/historia/filme-titanic

\section{RESUMO}

A presente resenha baseia-se na análise histórica do filme Titanic. O filme foi lançado em 19 de dezembro 1997 nos Estados Unidos - EUA, sendo escrito, dirigido, coproduzido e co-edificado por James Cameron. Entre os principais personagens podese destacar: Leonardo DiCaprio interpretando Jack Dawson, Kate Winslet interpretando Rose DeWitt Bukater, Glória Stuart interpretando Rose Calvert, Bill Paxton interpretando Brock Lovett, Billy Zane interpretando Cal Hockley, Kathy Bates interpretando Molly Brown, Frances Fisher interpretando Ruth DeWitt Bukater, Bernard Hill interpretando o Capitão Edward J. Smith, Jonathan Hyde interpretando J. Bruce Ismay, e Victor Jay Garber interpretando o engenheiro Thomas Andrewns. Trilha sonora composta por James Horner (compositor da música-tema), intérprete (músicas do filme) Céline Dion, e letrista Will Jennings. Equipe técnica composta pelo

${ }^{1}$ Graduada em Licenciatura Plena em Pedagogia pela Faculdade Internacional de Curitiba - PR, (FACINTER). Graduada em Licenciatura Plena em História - pela Faculdade Internacional de Curitiba (FACINTER). Graduanda de Licenciatura Plena em Sociologia - Turma de Outubro de 2017 da (FACINTER). Especialização em Educação Especial e Inclusiva (FACINTER). Especialização em Docência no Ensino Superior pela Faculdade de Educação São Luís de São Paulo - SP. Especialização em Gestão Escolar: Orientação e Supervisão pela Faculdade de Educação São Luís - SP. Especialização em Ensino Lúdico pela Faculdade de Educação São Luís - SP. 
diretor de fotografia Russell Carpenter, montador James Cameron, e Conrad Buff. Diretor de arte Martin Laing, engenheiro de som Gary Rydstrom, e Gary Summers. Editor dos efeitos especiais e supervisor de efeitos visuais Rob Legato. Empresas envolvidas na produção do filme: 20th Century Fox, Lightstorm Entertainment, Paramount Pictures. Efeitos visuais Digital Domain, distribuidor brasileiro (lançamento) Fox Film do Brasil. Efeitos especiais Industrial Light \& Magic (ILM).

Palavras-Chaves: Titanic, Navio, luxo, engenharia.

\section{INTRODUÇÃO}

É inegável a repercussão da obra de James Cameron lançada em 1997 que rendeu 11 Oscars, batendo recordes de premiações e bilheterias. A obra de Cameron retratou a glória esperada em relação ao transatlântico, sendo ela própria a força motriz de uma nova imagem do navio, marcada pelas cores, tecnologia e vivacidade fazendo os espectadores "entrarem" na dramaturgia e possibilitando uma experiência particular do naufrágio.

O lançamento do filme Titanic foi um sucesso mundial. O navio de luxo, construído na Irlanda do Norte no início do século XX, foi considerado uma "obra prima da engenharia". No dia 10 de abril de 1912 zarpava de Southampton, na Inglaterra, rumo à Nova York, nos Estados Unidos. Até então, o maior navio de passageiros já fabricado pelas mãos dos homens, o lendário Titanic. A história do Titanic narrada através de filmes e documentários, continua presente na memória de muitas pessoas por se tratar de uma história real e trágica. Não há como esquecer a tragédia da noite de 14 de abril para 15 de abril do ano de 1912.

O Titanic foi o navio mais moderno já construído no início do século XX. A obra do diretor James Cameron busca narrar a trajetória do RMS Titanic, considerado o "navio dos sonhos", e inafundável, assim como, a discriminação entre as classes sociais, a disputa de poder, e a história de amor de um jovem casal chamado Rose e Jack, de mundos completamente diferentes, os quais se conheceram e se apaixonaram durante a viagem inaugural do Titanic. 


\section{O TÃO ESPERADO EMBARQUE NO NAVIO TITANIC}

No filme é possível perceber o luxuoso e imponente Titanic no porto de Southampton, no Reino Unido, na Inglaterra, de partida para Nova York, nos Estados Unidos.

O Titanic enfeitiçou todos aqueles que o construíram ou que navegaram nele. Quanto mais os anos passam, mais fabulosa fica a lembrança de sua imagem. Os sobreviventes, pobres ou ricos, passageiros ou tripulantes, todos possuem duas qualidades em comum: de início, dão uma maravilhosa impressão de equilíbrio, como se o fato de ter passado por essa prova espantosa Ihes facilitasse a convivência com todos os problemas da existência. Sua velhice está impregnada de uma espécie de elegância e paz. Além disso, todos demostram um notável desprendimento, como se depois de terem testemunhados os maiores devotamentos e as maiores renúncias, tivessem passado o resto de suas vidas eliminando de si todo e qualquer traço de egoísmo. (LORD, 1999)

Aquela viagem prometia. Era uma viagem desejada, esperada por muitas pessoas, algumas atrás de negócios, outras em busca de refazerem suas vidas na América. $\mathrm{O}$ Titanic "parecia ser o navio dos sonhos" e realmente era.

O Titanic pode ser observado como uma célula que representa todo o conjunto social de seu tempo. Nele encontramos elementos de toda a estrutura social, desde os magnatas da aristocracia britânica e americana, os "novos ricos", camadas médias e as camadas inferiores. As formas de tratamento oferecidas aos passageiros que permeiam toda a primeira e única viagem do transatlântico não são uma forma isolada dos padrões sociais, mas uma continuidade daquilo que era praticado no continente. Da mesma forma, podemos entender o navio em sua totalidade, como uma continuidade da sociedade, cultura, economia e política administrada em terra firme.

De resto, aquele palácio flutuante espelhava a pirâmide social contemporânea. Na Primeira Classe, Jonh Jacob Astor e Benjamin Guggenheim. Na Segunda, a emergente classe média, constante de 
intelectuais, artistas e pequena burguesia que derivava da Revolução Industrial. Na terceira, os miseráveis agrumados nos conveses inferiores, em cabines de até dez leitos, que abandonavam os humílimos lares em busca de um sonho, a prosperidade que porventura encontrariam nos Estados Unidos (FARACO, 2006, p. 09)

\section{O PAPEL DOS PROTAGONISTAS NO FILME}

Nota-se no decorrer do filme, que Rose DeWitt Bukater é uma moça nobre, de classe alta, religiosa, talentosa, elegante, aprecia as belas artes, mas vive sufocada em seu meio social, pois se sente infeliz, sempre cercada das mesmas pessoas, "pessoas vazias, com conversas sem conteúdo". Já Jack Dawson é um moço alegre, um aventureiro que ganha em uma mesa de jogo, uma passagem para o Titanic. Rapaz de classe baixa, talentoso com as mãos, tem dom para desenhar, é um verdadeiro artista, educado, meigo, sonhador, nada passa despercebido diante de seus olhos. Tudo é registrado em suas folhas de papel através da arte.

Contudo, Jack Dawson é excluído pela elite, certamente por não ter grandes fortunas, ou seja, por não se "encaixar" nos padrões exigidos pelos nobres da época.

A história de amor de Rose e Jack chamou a atenção do público. Não teria como não chamar, uma jovem de família rica, esplêndida, prendada, termina seu noivado com o empresário chamado Cal Hockley, para viver um grande amor com Jack. Cal Hockley era um homem arrogante, perturbador, insensível com as diferenças, ditador e controlador da vida de sua noiva Rose.

Rose se sentia angustiada, sem ninguém para livrar ela daquele noivado infeliz, pois não amava Cal, tudo que ela sentia era como se estivesse em um grande precipício, gritando com todas as forças e ninguém a pudesse ouvi-la, ou ajudá-la. Para "acabar com sua infelicidade" Rose tenta contra sua própria vida, ameaçando se jogar do Titanic direto nas águas gélidas do oceano. No entanto, Jack ao ver aquela cena, se aproxima e convence Rose a não se jogar para fora do navio em movimento. 
Já Ruth DeWitt Bukater, mãe de Rose, fazia questão do casamento com Cal, e privava Rose de ver outros rapazes, como Jack, pois sonhava com a filha casada com o empresário, para assegurar a sobrevivência de ambas, as quais só tinham o sobrenome para "jogar", pois estavam falidas, com uma herança de dívidas.

\section{DESENVOLVIMENTO}

Ainda hoje, é possível observar que algumas pessoas não conhecem a história verídica e os objetivos da construção do gigante dos mares, talvez por não se informarem sobre o assunto, sobre os fatos em torno da verdadeira história do fabuloso transatlântico.

Percebe-se, que muitos sujeitos têm seu olhar voltado para a história de amor dos personagens (Rose e Jack), e não para o naufrago, sendo que a história de amor é a mais pura ficção do diretor James Cameron. O filme Titanic foi manipulado em algumas partes, o qual não é totalmente histórico, no entanto, é muito útil, e de grande valia para a pesquisa histórica, para a reflexão humana, e para a análise dos fatos ocorridos.

Já a cena do colar "The Heart of the Ocean" (o Coração do Oceano) presente dado a Rose pelo seu noivo Cal, e a cena de nudez da atriz ao ser desenhada por Jack com o colar, deu um destaque todo especial na obra de Cameron. De certo modo, a relação amorosa do casal chamou mais atenção do que a própria tragédia em si, isto é, a história de amor desviou em certa parte, o olhar crítico, analítico e sensível sobre a lamentável tragédia da noite de 14 de abril para 15 de abril de 1912, em meio ao Atlântico Norte no Canadá, aonde 1.500 (mil e quinhentas), pessoas perderam suas vidas nas águas negras e gélidas do oceano.

Em 15 de abril de 1912, o Titanic da White Star, o maior e mais luxuoso transatlântico do mundo, desaparecia no Atlântico Norte, durante a travessia inaugural, ao Sul da Terra Nova, no Canadá, depois de se chocar com um iceberg. 
A emoção foi intensa no mundo inteiro e o drama do gigante dos mares tomou proporções de uma catástrofe internacional. Emoção ainda mais viva porque essa magnífica embarcação, obra-prima da engenharia, parecia marcar uma etapa decisiva na história da construção naval e era considerada insubmersível. (MASSON, 2011, p. 7)

No decorrer do filme, é impossível não se emocionar com o relato da atriz Rose Calvert. A senhora Rose interpreta o papel fictício de uma sobrevivente do naufrago do RMS Titanic, a qual se emociona ao narrar detalhes muito presentes em sua memória. Trecho da fala de Rose: Foi há 84 anos, ainda sinto o cheiro da tinta fresca, das porcelanas nunca usadas, dos lençóis nunca usados, o Titanic se chamava "o navio dos sonhos", e era, realmente era.

O amor por Jack é revivido, a tragédia e as mortes ocorrida na viagem inaugural também é lembrado por Rose. A atriz se lamenta pelas 1.500 vidas que não puderem ser salvas das águas gélidas do oceano, entre elas a do seu amado Jack Dawson. Ainda sobre Jack, Rose acrescenta, (ele me salvou de todas as formas que uma pessoa poderia ser salva).

O naufrago do Titanic foi e continua sendo a maior tragédia de todos os tempos. No entanto, a comunicação sem fio revela a sua importância para a segurança no mar.

Com o Titanic, não há dúvida de que as mensagens pelo rádio evitaram que os sobreviventes, perdidos em meio ao gelo, conhecessem um destino trágico. Se a catástrofe tivesse ocorrido dez anos antes, eles teriam morrido de frio e de esgotamento nos botes. O desaparecimento do gigante dos mares estaria inscrito, com certeza, entre os grandes enigmas da história marítima. (MASSON, 2011, p. 155)

De qualquer modo, fica impossível de se negar que o Titanic não trouxesse consigo certa arrogância em sua construção, ou no mínimo, um orgulho nascente de um projeto bem sucedido. Esse orgulho e arrogância produzem um fruto funesto, que 
também possui a sua margem de responsabilidade no naufrágio ao lado do iceberg, trata-se de negligência:

O drama do Titanic parece, definitivamente, explicar-se pela negligência e pela fatalidade. Negligência do operador de rádio que não transmitiu à ponte de comando duas mensagens de importância capital. Negligência dos oficiais que se recusaram a fornecer, contrariando o que e habitual, binóculos aos vigias, apesar de numerosas reclamações. Negligência do próprio capitão que, não adotando o hábito de alguns comandantes, não reuniu, no final do dia, os oficiais destinados a assumir o quarto da noite, para estudar com eles a situação geral. (MASSON, 2011, p. 140)

O filme Titanic, na obra de James Cameron, apresenta pontos significativos sobre a viagem inaugural e o naufrágio em meio ao Atlântico Norte no Canadá. Realmente Cameron buscou relatar o naufrago de forma construtiva, narrando o desespero dos passageiros quando comunicados que o Titanic iria afundar. Infelizmente o iceberg danificou severamente o casco do navio, Titanic não resistiu ao choque, e se dividiu ao meio.

Analisa-se, que a Primeira Classe foi a mais favorecida no salvamento de suas vidas, já a Terceira Classe a mais atingida pela dor, pelo sofrimento, pela perda de vidas humanas. Excluídos simplesmente por se tratar da Terceira Classe, grupo de pessoas que não se "encaixavam" nos padrões dos nobres, pois não tinham grandes fortunas, ou objetos de alto valor para oferecer ou demonstrar.

\section{CONSIDERAÇÕES FINAIS}

Conclui-se que, no final do século XIX e início do século XX, o que prevalecia era o capital, e a disputa de poder no Atlântico. O Titanic surgiu de um projeto ambicioso, de uma competição marítima acirrada entre os países desenvolvidos. 
No entanto, Titanic deixou uma lição valiosa para a humanidade. É fato que fortunas e bens materiais conseguimos e recuperamos através de esforços e trabalho, mas a vida nunca se recupera.

Que soubemos refletir diariamente, que nenhum capital ou disputa, vale mais que uma vida. Todo projeto é falível, e necessita de um plano construtivo no que diz a segurança. Projetos jamais podem ser pensados e realizados para desafiar a vida humana e as leis da natureza, como foi o caso do Titanic.

\section{REFERÊNCIAS}

CORDEIRO, Gisele do Rocio. Orientações e dicas práticas para trabalhos acadêmicos/ Gisele do Rocio Cordeiro; Nilcemara Leal Molina; Vanda Fattori Dias (Org.). - 2.ed. revisada e atual. - Curitiba: InterSaberes, 2014, 181 p. Bibliografia. ISBN 978-85-8212-967-8.

FARACO, Sergio. O crespúsculo da arrrogância: RMS Titanic minuto a minuto. Porto Alegre: L\&PM, 2006, p. 9

LORD, Walter. A tragédia do Titanic. São Paulo: Presença, 1999.

MASSON, Philippe. Titanic: A história completa/ Philippe Masson; tradução Angela M. S. Corrêa. - 1. ed. $1^{\circ}$ reimpressão. - São Paulo: Editora Contexto, 2015, 265 p. Título original: Le drama du Titanic. Bibliografia ISBN 978-85-7244-691-4.

SIENNA, Kleber. Titanic, o legado do grande navio: Permanências e alterações no imaginário das catástrofes. Universidade Federal de Uberlândia: Instituto de História, 2018.

TITANIC. Direção: James Cameron. EUA: Twentieth Century Fox \& Paramount Pictures, 1997. 1 filme (194min).

Enviado: Dezembro, 2018.

Aprovado: Março, 2020. 